\title{
TUTOR'S COLUMN
}

\section{David Burch, Clinical Tutor}

'Modernising Medical Careers' is the main issue occupying the education specialists nationally. This is an attempt to explain what it means for consultants and their teams in the Morecambe Bay area.

There are several elements to this. Foundation programmes have to be organised: this includes deciding on the placements, the educational programmes and assessment of the doctors.

Locally we have made good progress on the placements, and for Lancaster/Westmorland the F2 programme for those graduating in 2005 is nearly decided - it will certainly include obstetrics and gynaecology, peri-operative medicine, medicine, and some of the posts currently held by basic surgical trainees, as well as General Practice.

There will also be a cross-Bay pilot F2 running in August 2005 .

\begin{tabular}{|l|l|l|}
\hline WGH Medicine & Peri-operative Medicine RLI & GP Lancaster \\
\hline WGH Medicine & $\begin{array}{l}\text { Obstetrics \& } \\
\text { Gynaecology RLI }\end{array}$ & $\begin{array}{l}\text { GP Kendal/ } \\
\text { Lancaster }\end{array}$ \\
\hline WGH Medicine & $\begin{array}{l}\text { Obstetrics \& } \\
\text { Gynaecology RLI }\end{array}$ & $\begin{array}{l}\text { GP Kendal/ } \\
\text { Lancaster }\end{array}$ \\
\hline WGH Medicine & $\begin{array}{l}\text { Accident \& Emergency } \\
\text { Department FGH }\end{array}$ & GP Barrow \\
\hline WGH Medicine & $\begin{array}{l}\text { Accident \& Emergency } \\
\text { Department FGH }\end{array}$ & GP Barrow \\
\hline
\end{tabular}

This pilot is important in several ways. It will give us practice in the educational programme and assessment methods (see below) and will also ensure a cohort of doctors ready to apply for SHO posts in 2006 - if no-one did a pilot then every 2005 graduate would be doing F2 in 2006 and no-one would enter GP or specialist training that year!

\section{ASSESSMENT OF FOUNDATION DOCTORS}

Assessment of doctors is a hot topic. Early identification of needs for additional training is important. The process of recommending additional training has to be handled sensitively and its needs have to be backed up by robust assessment and appropriate documentation of a sort that may have to be scrutinised in the event of an appeal. For practising clinicians there is also the need not to be overwhelmed by paper exercises.

The consultation paper on the curriculum and assessment in the Foundation Years has now been published, and I have attended the National Association of Clinical Tutors meeting on assessment and a Modernising Medical Careers assessment workshop. There are four main assessment tools that we will have to use with these doctors.

\section{Peer Assessment Tool (PAT)}

This is the new name for 360 degree appraisal; it is also sometimes called Multi Source Feedback. The pilot sites have used various forms of greater or lesser complexity and I am strongly persuaded by the argument that only four fields are necessary. When this starts it will be a paper-based system; the trainee will give an assessor nomination form to the trust foundation co-ordinator, who will distribute the PAT form. The trainees assess themselves on the same form to see how much insight they have. These will then be sent to a collating person. The normal model in the pilots has been for the Education Centre to bundle them up and post them to some central place every fortnight or so. Feedback will be provided via the educational supervisor.

The raters will include consultants or GPs, together with specialist registrars, nurses, midwives and allied health professionals. The forms are not designed for use by either patients or clerical staff. It is unlikely to take the raters more than five minutes to fill in these forms so the main resource implications would be the clerical effort in the Education Centre to gather together the forms and despatch them to the deanery; or the installation, training and maintenance of an electronic system when that replaces it.

\section{Mini Clinical Evaluation Exercise (mini-CEX)}

Trainees should carry out six observed clinical encounters over a year, two in each four-month appointment. Each should be observed by a different supervisor and in each post one should be the consultant taking clinical responsibility for that trainee, the other could be a specialist registrar or another consultant. These are supposed to last 20 minutes to cover a range of clinical problems, sampling the different acute care categories listed in the curriculum, and the trainee is supposed to have a say in the timing, the problem and the observer. Over the year the cases should cover a wide spectrum, eg new outpatient, elective admission, emergency admission, taking consent, discharge advice. Where complex problems are being managed the assessment covers a 20 minutes segment of the whole clinical encounter.

\section{Direct Observation of Procedural Skills (DOPS)}

It is anticipated that there will be six of these during the course of a calendar year, two in each of the four-month attachments, and that each will take 20 minutes. The observer need not be a consultant or GP principal but could be an SpR, nurse or allied health professional and again the trainee is supposed to choose timing, procedure and observer. The selected range of skills given in the curriculum is rather strange with most of them being no more complex than taking blood or siting a drip, while airway management is also there which is a much more technical task and is likely to be carried out in an emergency. There is also an 'other' category and I think educational leaders will now need to give some thought to what that would be for their specialty. For example, in gynaecology passing a speculum, taking a smear and endocervical swabs would be highly appropriate for a directly observed procedure. In A\&E, suturing a small wound would be suitable. Again, the formal time required is two hours per trainee per year.

\section{Case-Based Discussion}

This involves 20 minutes per case with six over the course of a year and is a structured discussion starting from an entry made in the case notes by the trainee. The educational supervisor will be asking the trainee questions such as: What was your differential diagnosis? Why did you request the test? How did it alter your management? Once again, in each four-month 
attachment the trainee will have one session with the supervising consultant and one with somebody else so they get six different assessors over the year.

\section{WHAT HAPPENS AFTER FOUNDATION YEARS?}

If anyone knows please would they tell me? Each specialty is designing a plan for further training. In some specialties this will be a 'run through grade'. The best example of this is probably urology, in which trainees will be brought to the point of being able to do a diagnostic cystoscopy and other more minor procedures, at which time they will be called a consultant urologist. A minority of these doctors will carry out further training to be able to do the full range of major surgery, and will be called consultant urological surgeons. In obstetrics and gynaecology we may see SHO-level trainees working almost exclusively on labour ward to get them ready for resident-on-call as soon as possible.

It is also likely that all doctors in training will have similar assessments to those described above. There is an MMC timeline on the website which I reproduce here.

\begin{tabular}{|ll}
\hline Foundation programme curriculum published & 31 March 2005 \\
\hline $\begin{array}{l}\text { Operational framework } \\
\text { Rough guide to the foundation programme for } \\
\text { trainers and medical students }\end{array}$ & April 2005 \\
\hline $\begin{array}{l}\text { Selection methods for specialist training } \\
\text { agreed in principle }\end{array}$ & April 2005 \\
\hline Foundation programme begins 2005 \\
\hline SAS grade restructuring plan agreed & August 2005 \\
\hline $\begin{array}{l}\text { Specialty review conclusions } \\
\text { Workforce transition management }\end{array}$ & September 2005 \\
\hline $\begin{array}{l}\text { arrangements agreed } \\
\text { selection agreed }\end{array}$ & October 2005 \\
\hline First MMC cohort enters specialist training & August 2007 \\
\hline
\end{tabular}

\section{FURTHER READING}

www.mmc.nhs.uk

\section{ACKNOWLEDGEMENTS}

Some of this article is based on material by Dr Andy Craven, associate director of General Practice.

\section{NORTH WESTERN DEANERY FOUNDATION ASSESSMENT WORKSHOPS}

\section{BACKGROUND}

This August sees the start of one of the most significant changes to postgraduate medical education in recent times Modernising Medical Careers (MMC). The newly qualified doctors in August will embark upon a two-year training programme, Foundation Training, designed to equip them with the necessary knowledge, skills and attitudes to undertake a specialty career path in the future. Underpinning Foundation Training is a requirement for trainees to demonstrate a range of generic competencies in clinical examination, case-based discussion, practical procedures and peer review of performance. These competencies will form a portfolio of evidence which will provide the means of completing Foundation Training and continuing their medical careers.

Clinical and Educational Supervisors are going to have an increasingly important role in MMC, particularly in the area of the above assessments, as they will be required to perform the assessments and give feedback on performance. It is necessary, therefore, for those undertaking these assessments to familiarise themselves with the tools.

\section{LEARNING OUTCOMES}

By attending these workshops participants will be able to undertake:

a) Assessment and feedback for a mini clinical examination (mini-CEX)

b) Assessment and feedback for a directly observed practical skill (DOPS)

c) Assessment and feedback for a case-based discussion (CBD)

d) Feedback following completion of a peer assessment tool (mini-PAT)

Learning Methods:

Participants will work in small groups, facilitated by an experienced tutor, and discuss the issues involved in marking and feedback for the above exercise.
A video of a mini-CEX, DOPS and CBD will form the basis for discussion and calibration of marks.

For mini-PAT, participants will be given the results of an assessment exercise and discuss the feedback issues raised.

Time:

Each workshop is scheduled to last three hours.

Resources:

At the end of the workshop participants will be asked to complete an evaluation sheet. Each health economy will be issued with a DVD enabling them to undertake similar workshops within their locality.

\section{ASSESSMENT WORKSHOPS}

\begin{tabular}{|c|c|c|}
\hline Date & & Venue \\
\hline \multirow[t]{2}{*}{ June 7 th } & am & \multirow[t]{2}{*}{ Oak House, Burnley } \\
\hline & $\mathrm{pm}$ & \\
\hline \multirow[t]{2}{*}{ June 9th } & am & \multirow[t]{2}{*}{ JJB, Wigan } \\
\hline & $\mathrm{pm}$ & \\
\hline \multirow[t]{2}{*}{ June 21st } & am & \multirow{2}{*}{ Bredbury Hall, Stockport } \\
\hline & $\mathrm{pm}$ & \\
\hline \multirow[t]{2}{*}{ June 22nd } & am & \multirow[t]{2}{*}{ Reebok, Bolton } \\
\hline & $\mathrm{pm}$ & \\
\hline \multirow[t]{2}{*}{ June 28th } & am & \multirow[t]{2}{*}{ Lancaster House, Lancaster } \\
\hline & $\mathrm{pm}$ & \\
\hline \multirow[t]{2}{*}{ June 29th } & am & \multirow[t]{2}{*}{ Bredbury Hall, Stockport } \\
\hline & $\mathrm{pm}$ & \\
\hline \multirow[t]{2}{*}{ July 7th } & am & \multirow[t]{2}{*}{ JJB, Wigan } \\
\hline & $\mathrm{pm}$ & \\
\hline \multirow[t]{2}{*}{ July 19th } & am & \multirow[t]{2}{*}{ Grange Hotel, Grange-Over-Sands } \\
\hline & $\mathrm{pm}$ & \\
\hline \multirow[t]{2}{*}{ July 20th } & am & \multirow{2}{*}{ Reebok, Bolton } \\
\hline & $\mathrm{pm}$ & \\
\hline
\end{tabular}

